\title{
Synthesis and Evaluation of Magnetic Nanoparticles for Biomedical Applications
}

\author{
Nydeia W. Bolden, ${ }^{1}$ Vijaya K. Rangari, ${ }^{1}$ Shaik Jeelani, ${ }^{1}$ Seyhan Boyoglu, ${ }^{2}$ and Shree R. Singh ${ }^{3}$ \\ ${ }^{1}$ Department of Materials Science and Engineering, Tuskegee University, Tuskegee, AL 36088, USA \\ ${ }^{2}$ Department of Pediatrics, Emory-Children's Center, Emory University, Atlanta, GA 30322, USA \\ ${ }^{3}$ Center for NanoBiotechnology Research, Alabama State University, Montgomery, AL 36104, USA
}

Correspondence should be addressed to Vijaya K. Rangari; rangariv@mytu.tuskegee.edu

Received 24 October 2012; Revised 25 December 2012; Accepted 27 December 2012

Academic Editor: Fabien Grasset

Copyright (C) 2013 Nydeia W. Bolden et al. This is an open access article distributed under the Creative Commons Attribution License, which permits unrestricted use, distribution, and reproduction in any medium, provided the original work is properly cited.

In this study, iron oxide (IO) nanoparticles from various precursors have been synthesized using sonochemical method and characterized for their structural variability and toxicity. The iron oxide (IO) precursor solutions were prepared from iron acetate (IA), iron pentacarbonyl (IP), decalin, PEG (poly(ethylene glycol)), EG (ethylene glycol), PVA (poly(vinyl alcohol)), $\beta$-cyclodextrin (CD), and distilled water. These precursor solutions were irradiated with high power ultrasound for 3 hours and heat treated as needed. These as-prepared iron oxide nanoparticles were characterized using X-ray diffraction (XRD), Mössbauer spectroscopy, transmission electron microscopy (TEM), and magnetization measurements. XRD results show that all the particles are highly crystalline in nature and the particles sizes measured from TEM are approximately $5-20 \mathrm{~nm}$. The maximum magnetization was observed for IO-IP at approximately $60.17 \mathrm{emu} / \mathrm{g}$ and the minimum was approximately $30.56 \mathrm{emu} / \mathrm{g}$ for IO-IA. These results confirm that the particles are superparamagnetic (SPM) in nature. Mössbauer spectroscopy verified the magnetic nanoparticles are purely $\mathrm{Fe}_{3} \mathrm{O}_{4}$ and particles sizes varied by the nature of the precursor and coatings.

\section{Introduction}

Iron based nanomaterials have found applications in many areas of science and technology due to their unique magnetic properties [1-5]. Recently, they are also used in biomedical applications such as MRI contrast agents for imaging [6], magnetic hyperthermia [7], and targeted drug delivery [8] because of their size compatibility [9] to cells, genes, and viruses. A size reduction of these materials from bulk to the nanoscale permits them to display various size related properties. Among other changes, a significant decrease in size can alter reactivity, increase surface area, and change the magnetic properties [10-12]. Iron oxide, for example, exhibits ferromagnetic behavior in bulk where it can reach full magnetization and the effect persists even after removal of the magnetic field. These same particles below a certain size $(<20 \mathrm{~nm})$ may exhibit a behavior similar to paramagnetism even when at temperatures below the Curie point. This is a nanoscale phenomenon, where the energy required to change the direction of the magnetic moment of a particle is comparable to the ambient thermal energy. The energy required to change the direction of magnetization of a crystallite is called the crystalline anisotropy energy and depends both on the material properties and the crystallite size. As the crystallite size decreases, so does the crystalline anisotropy energy, resulting in a decrease in the temperature at which the material becomes superparamagnetic. These materials require the presence of a field to align their magnetic moments and magnetize. They lose most or all of their magnetization once the field is removed.

SPM materials are potential candidates for targeted drug delivery applications because of their size compatibility and ability to become highly magnetized only in the presence of a magnetic field. Magnetic particles performing as drug carriers [13] involve systems that can be directed through the body to a specific location by an external magnet. The significance of these drug systems is perhaps most imperative in the area of chemotherapy where severe side effects such as 
morphological alterations and functional impairment of the heart can occur [14]. Cancer drugs perform by killing cancer cells, but are not restricted and consequently affect healthy cells as well. The side effects of these drugs may decrease while the effectiveness is increased if a majority of the drug is able to reach its targeted site. With the aid of an external magnet placed near the desired location, more of these drugs should be able to reach its destination and harm fewer healthy cells.

Due to the nature of these applications, which involves interactions with a magnetic field outside the body, it is necessary to use materials that can reach the highest possible magnetization. Currently, iron oxide, particularly magnetite $\left(\mathrm{Fe}_{3} \mathrm{O}_{4}\right)$, is commonly studied for these applications over other iron oxide structures such as maghemite $\left(\gamma-\mathrm{Fe}_{2} \mathrm{O}_{3}\right)$ due to a higher magnetic saturation [15]. Similar synthesis routes can be used to produce either structure and require detailed analysis such as XRD and Mössbauer spectroscopy to determine the specific phase. Peaks for both $\mathrm{Fe}_{3} \mathrm{O}_{4}$ and $\gamma$ - $\mathrm{Fe}_{2} \mathrm{O}_{3}$ occur at nearly the same $2 \theta$ in XRD, making it difficult to distinguish. $\mathrm{Fe}_{3} \mathrm{O}_{4}$ can be identified by Mössbauer spectra taken at room temperature by the display of hyperfine magnetic splitting that is not seen in $\mathrm{Fe}_{2} \mathrm{O}_{3}[16,17]$.

Iron oxide nanoparticles for drug delivery applications can be synthesized through various methods including solution precipitation, decomposition, ultrasound chemistry, and microwave heating [18-20]. Sonochemical techniques, the method used in this study proceeds by the creation, formation, and bursting of cavitations created from ultrasound waves. When the bubble collapses, it generates pressures and temperatures high enough to cause bond breakage. Because the cooling rates are also high, the particles' size remains low, and only nanosized materials are produced. This method has been proven by Suslick [21] and others [22-25] as a reliable, reproducible, and relatively easy way to synthesize both uncoated and in situ coated materials. All particles created for biorelated applications must be biocompatible, and therefore may require additional coatings. Coatings can also provide water dispersion stability and protection from degradation as well as increasing circulation time [26]. Coatings may be added to the surface of the oxides through chemical or physical bonding [27] using techniques such as solvent evaporation and coupling agents [28] and can take place either in situ or after-synthesis. Commonly used coatings include poly(lactic-co-glycolic acid) (PLGA) [29], Polyethylene glycol (PEG) [30], Poly vinyl alcohol (PVA), [31] and pluronic-127 [32]. The efficiency of these coatings can be determined through cell viability studies at various concentrations of nanoparticles [33]. In this study a uniform superparamagnetic $\mathrm{Fe}_{3} \mathrm{O}_{4}$ nanoparticles were synthesized and characterized for their morphology, structural, magnetic and biocompatibility.

\section{Materials and Methods}

2.1. Materials. All materials including iron pentacarbonyl (99.99\%), iron(II)acetate (99.99\%), decalin (decahydronaphthalene, mix cis \& trans, reagent grade 98\%), PEG $\left(\right.$ avg $\left.20 M_{w}\right)$, EG, $\beta$-Cyclodextrin hydrate, and PVA $(99+\%$ hydrolyzed, avg $\left.M_{w} 85,000-146,000\right)$ were purchased from Sigma Aldrich.

2.2. Synthesis of $\mathrm{Fe}_{3} \mathrm{O}_{4}$ (IO-IP). IO-IP magnetic nanoparticles were synthesized using ultrasonic irradiation of iron pentacarbonyl $(2 \mathrm{~mL})$, decalin $(40 \mathrm{~mL})$, and PEG $(20 \mathrm{~mL})$ for $3 \mathrm{hrs}$ at $50 \%$ power using a high intensity ultrasonic horn (Tihorn, $20 \mathrm{kHz}, 100 \mathrm{~W} / \mathrm{cm}^{2}$ ). The reaction was carried out in open air within a stainless steel vessel at $30^{\circ} \mathrm{C}$ maintained by circulating water using a thermostat. The solution was diluted in ethanol and centrifuged (Allegra 64R centrifuge) at $15,000 \mathrm{rpm}$ at $5^{\circ} \mathrm{C}$. The precipitate was washed several times with ethanol and dried overnight under vacuum. The asprepared sample was analyzed using XRD, TEM, Mossbauer spectroscopy, and magnetic measurements.

2.3. Synthesis of PVA-Coated $\mathrm{Fe}_{3} \mathrm{O}_{4}$ (PVA-IO). Following the same procedure as shown above, except the reaction was carried out in the presence of PVA $(0.5 \mathrm{~g})$; the as-prepared sample was heated at $300^{\circ} \mathrm{C}$ for $3 \mathrm{hrs}$ to produce crystalline particles.

2.4. Synthesis of $\mathrm{Fe}_{3} \mathrm{O}_{4}(\mathrm{IO}-\mathrm{IA})$. Additional $\mathrm{Fe}_{3} \mathrm{O}_{4}$ nanoparticles were synthesized through ultrasonic irradiation of iron acetate $(1.0 \mathrm{~g})$, ethylene glycol $(40 \mathrm{~mL})$, and distilled $\mathrm{H}_{2} \mathrm{O}$ solutions $(100 \mathrm{~mL})$. The reaction was carried out in open air in a glass beaker placed in a water bath at room temperature to prevent overheating and followed the same procedure as described earlier to obtain final product for characterization.

2.5. Synthesis of $\beta$-Cyclodextrin-Coated $\mathrm{Fe}_{3} \mathrm{O}_{4}$ (CD-IA). $\beta$ cyclodextrin-coated $\mathrm{Fe}_{3} \mathrm{O}_{4}$ was produced from iron acetate $(1 \mathrm{~g})$, ethylene glycol $(40 \mathrm{~mL})$, distilled $\mathrm{H}_{2} \mathrm{O}(100 \mathrm{~mL})$, and $\beta$ cyclodextrin (500 mg), using the IO-IA procedure.

2.6. Testing Method. XRD analysis was carried out on a Rigaku Diffractometer (D-MAX2000) from $3-80^{\circ}$ of $2 \theta$ at a scan speed of $0.200^{\circ} / \mathrm{min}$. Samples were prepared by spreading the powdered specimen on a glass holder using ethanol; the powder dried before testing. TEM studies were conducted using a JEOL-2010 transmission electron microscope. Samples were prepared by dropping a colloidal solution of ethanol nanoparticles onto a carbon-coated (200 mesh) copper grid. Magnetization curves were obtained at room temperature in an induced magnetic field of 2-20 kOe using a Princeton Measurement Micromag. These samples were prepared by placing a $200 \mathrm{mg}$ of solid sample at the end of the flexible fiber and mounted perpendicular to magnetic field. The mass of the sample was calculated excluding the coating of PVA or CD.

The Mössbauer measurements were carried out using a conventional constant acceleration spectrometer operated in multichannel scaling mode. The gamma ray source used for the sample determinations and for iron-57 velocity calibrations consisted of $12 \mathrm{mCi}$ of $\mathrm{Co}^{57}$ in a rhodium metal matrix that was maintained at ambient temperature throughout spectral determinations. Using the latter source allowed for 
realization of reasonably high $\mathrm{S} / \mathrm{N}$ velocity spectra in collection times approximately 24 to 48 hours. The spectrometer was calibrated using a 6-micron thick natural abundance iron foil. The center of the magnetic hyperfine pattern of the latter foil (at ambient temperature) is taken as zero velocity. The line widths of the inner-most pair of $\Delta M_{\mathrm{I}}= \pm 1$ transitions of the latter Zeeman pattern were reproducibly determined to be $0.214 \mathrm{~mm} / \mathrm{s}$. The as-prepared samples were placed in nylon sample holders of $1 \mathrm{~cm}^{2}$ cross-sectional area for transmission Mössbauer spectroscopy experiments.

2.7. Cell Cytotoxicity of Nanoparticles. HEp-2 cells were purchased from the American Type Culture collection (ATCC, Manassas, VA; CCL-23) and were propagated by standard methods using minimum essential medium (MEM) supplemented with $10 \%$ fetal bovine serum (FBS), $2 \mathrm{mM}$ L-Glutamine, $75 \mathrm{U} / \mathrm{mL}$ penicillin, $100 \mu \mathrm{g} / \mathrm{mL}$ kanamycin, and $75 \mu \mathrm{g} / \mathrm{mL}$ streptomycin. The effect of nanoparticles on cytotoxicity was measured by MTS (3-(4,5-dimethylthiazol-2-yl)-5-(3-carboxymethoxyphenyl)-2-(4-sulfophenyl)$2 \mathrm{H}$-tetrazolium) dye reduction. HEp-2 cells were seeded in a 96-well plate at a density of 20,000 cells per well in MEM containing 5\% FBS and grown overnight. After 24, 48, and $72 \mathrm{~h}$ after-incubation of nanoparticles complexes, media were removed and cells were washed twice with sterile PBS. $20 \mu \mathrm{L}$ of MTS $(5 \mathrm{mg} / \mathrm{mL})$ in sterile filtered PBS was added to each well and then incubated for $2 \mathrm{~h}$ to allow formation of formazan crystals at $37^{\circ} \mathrm{C}$. After $2 \mathrm{~h}$, the absorbance of formazan products was measured at $490 \mathrm{~nm}$ using a microplate reader.

\section{Results and Discussion}

XRD analysis was carried out to determine the amorphous/ crystalline nature and impurities in the as-prepared nanoparticles. Figure 1 shows the XRD patterns of (a) as-prepared IO-IP, (b) PVA-IP heated at $300^{\circ} \mathrm{C}$, (c) IO-IP heated at $300^{\circ} \mathrm{C}$, (d) as-prepared CD-IA, and (e) as-prepared IO-IA. The powder X-ray pattern of Figure 1(a) clearly shows the asprepared uncoated, unheated sample synthesized from iron pentacarbonyl is highly amorphous and no crystalline peaks were observed. To further analyze the amorphous material, XRD was carried out for IO-IP (Figure 1(c)) heated to $300^{\circ} \mathrm{C}$ in an argon atmosphere. Figure 1(c) shows that the particles are highly crystalline and all the diffraction peaks match very well with magnetite JCPDS file number 19-0629. No impurities were observed in this sample. Figure 1(b) shows PVA-IO heated at $300^{\circ} \mathrm{C}$ in argon atmosphere is also highly crystalline in nature and all peaks match with magnetite JCPDS file number 19-0629.

The XRD diffraction patterns of as-prepared particles synthesized from iron acetate (IO-IA) are shown in Figure $1(\mathrm{e})$. These diffraction peaks illustrate the highly crystalline nature of the particles. No XRD detectable impurities were observed in this sample as well. Unlike the iron oxide particles produced from the iron pentacarbonyl precursor, these iron oxides were highly crystalline and did not need any additional heat treatments. The peaks were also matched

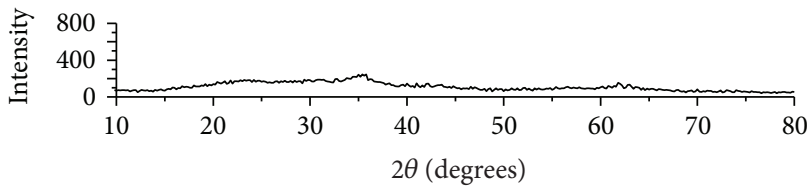

(a)

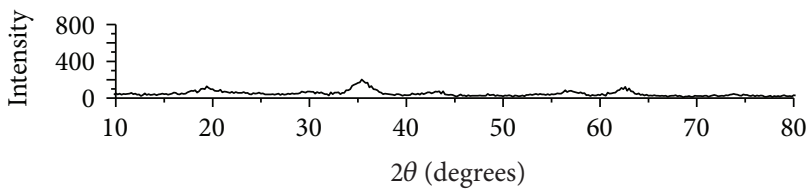

(b)

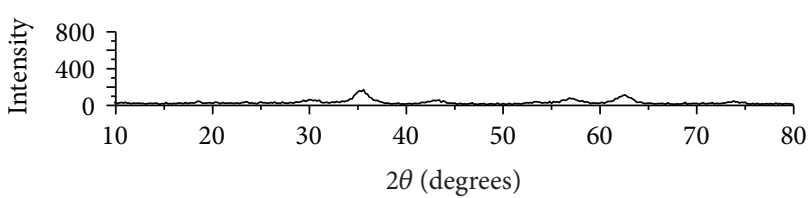

(c)

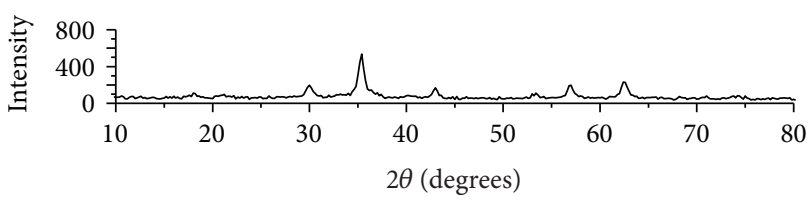

(d)

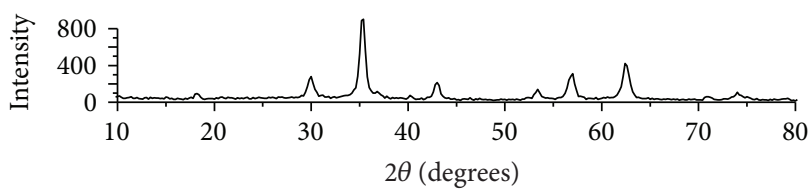

(e)

FIGURE 1: XRD patterns of (a) as-prepared IO-IP, (b) PVA-IP heated at $300^{\circ} \mathrm{C}$, (c) IO-IP heated at $300^{\circ} \mathrm{C}$, (d) as-prepared CD-IA, and (e) as-prepared IO-IA.

TABLE 1: Magnetization and coercive field values of $\mathrm{Fe}_{3} \mathrm{O}_{4}$ nanoparticles synthesized from various precursors and solvents.

\begin{tabular}{lcc}
\hline Sample & $H_{c}(\mathrm{Oe})$ & $M_{s}(\mathrm{emu} / \mathrm{g})$ \\
\hline IO-IP & 4.2 & 60.17 \\
PVA-IO & 9.9 & 31.32 \\
IO-IA & 16.9 & 30.56 \\
CD-IA & 25.4 & 36.92 \\
\hline
\end{tabular}

with the JCPDS file number 19-0629 for magnetite. Figure 1 (d) depicts the XRD of as-prepared CD-IA; the diffraction peaks clearly suggest that the as-prepared particles are also highly crystalline and all peaks match very well with the JCPDS number 19-0629 for magnetite. These XRD results visibly suggest that all the particles synthesized from various precursors and solvents produced only magnetite $\mathrm{Fe}_{3} \mathrm{O}_{4}$ nanoparticles with various coating.

TEM analysis was conducted to understand the morphology, surface coatings and crystal nature of the particles. Figure 2 represents the TEM micrograph of (a) IO-IP heated 


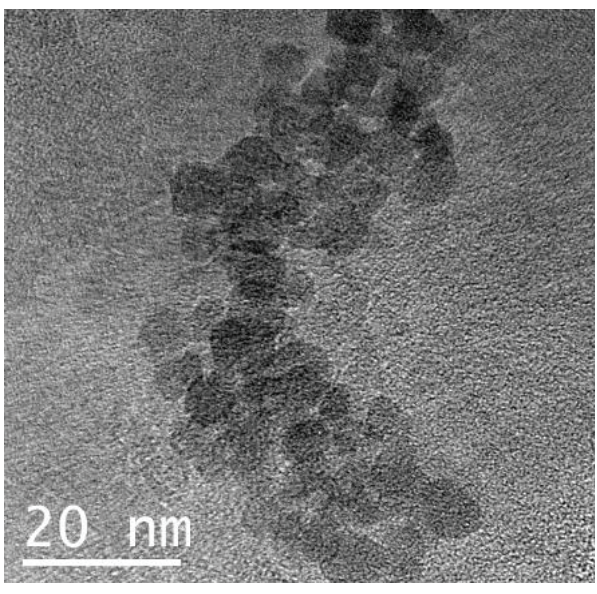

(a)

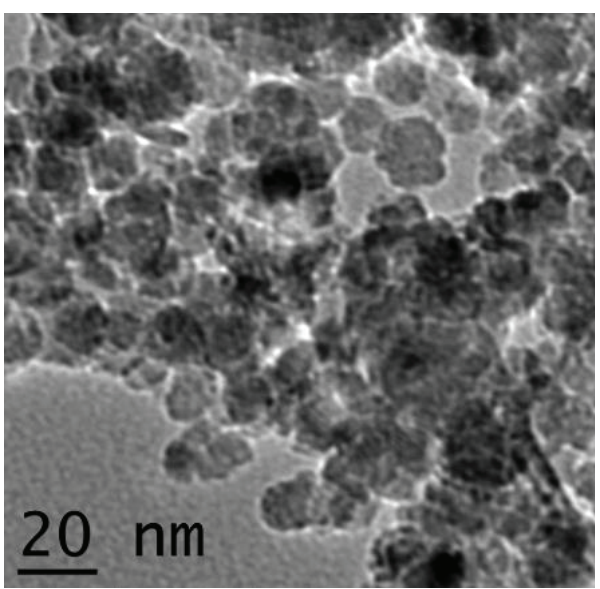

(c)

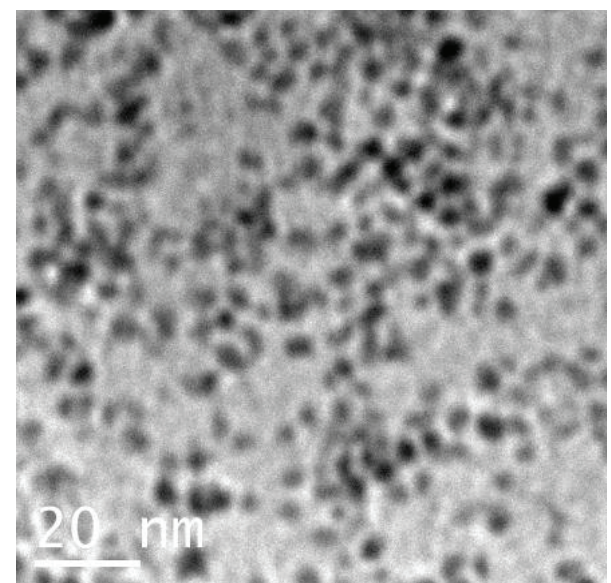

(b)

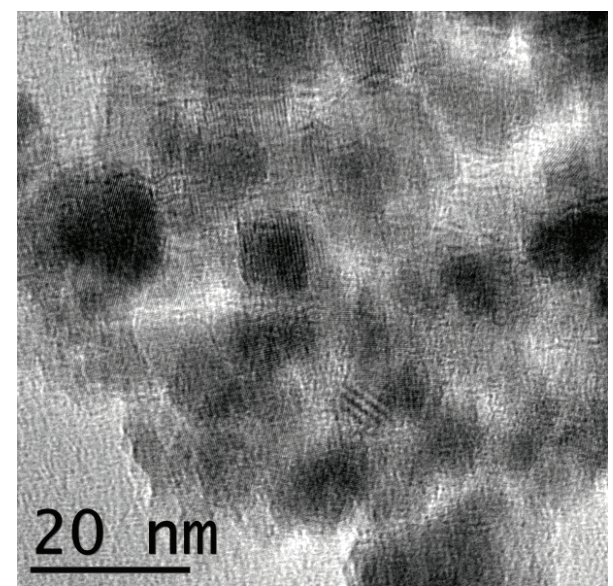

(d)

FIGURE 2: TEM micrograph of (a) IO-IP heated at $300^{\circ} \mathrm{C}$, (b) PVA-IO heated at $300^{\circ} \mathrm{C}$, (c) as-prepared IO-IA, and (d) as-prepared CD-IA.

at $300^{\circ} \mathrm{C}$, (b) PVA-IO heated at $300^{\circ} \mathrm{C}$, (c) as-prepared IOIA, and (d) as-prepared CD-IA. Figure 2(a) shows that the iron oxide nanoparticles prepared from iron pentacarbonyl precursor and heated at $300^{\circ} \mathrm{C}$ are highly crystalline in nature and spherical in shape. The particles sizes measured from the micrograph are about approximately 5-10 $\mathrm{nm}$. The nanoparticles prepared from PVA and iron pentacarbonyl are presented in Figure 2(b). The TEM micrograph shows that the particles are spherical in shape and are relatively less agglomerated when compared to the IO-IP heated sample with similar sizes. Figure 2(c) depicts the TEM micrograph of as-prepared iron oxide nanoparticles from IA. These particles are also spherical in shape and sizes measured are approximately $15-20 \mathrm{~nm}$ with a little agglomeration. The iron oxide nanoparticles prepared from IA in the presence of CD are presented in Figure 2(d). These particles are also spherical in shape, and uniformly dispersed, and the sizes measured are approximately $10 \mathrm{~nm}$ with minimum agglomeration. This micrograph also clearly shows the lattice structure of iron oxide nanoparticles. It is noteworthy to mention that all the iron oxide nanoparticles prepared are mostly spherical. Most importantly, the particle sizes observed in all of the samples fall within the critical limits for drug delivery applications and are small enough to allow for size increase due to additional coatings or drug loading without reaching above the limits. The PVA-coated particles seem to be completely embedded in the PVA, thereby providing an environment for drug loading, protection from potential oxidation encountered in vivo, and yielding a much more biocompatible material.

Magnetic properties were studied to determine the magnetic saturation and coercive field of (a) IO-IP heated at $300^{\circ} \mathrm{C}$, (b) PVA-IO heated at $300^{\circ} \mathrm{C}$, (c) as-prepared IO-IA, and (d) as-prepared CD-IA nanoparticles at room temperature are shown in Figure 3 and the results were summarized in Table 1. The magnetization/coercive field measured from Figure 3 is $60.17 \mathrm{emu} / \mathrm{g} / 4.23 \mathrm{Oe}, 31.32 \mathrm{emu} / \mathrm{g} / 9.92 \mathrm{Oe}$, $30.32 \mathrm{emu} / \mathrm{g} / 16.93 \mathrm{Oe}$, and $36.92 \mathrm{emu} / \mathrm{g} / 25.38 \mathrm{Oe}$, respectively, for (a) IO-IP heated at $300^{\circ} \mathrm{C}$, (b) PVA-IO heated at $300^{\circ} \mathrm{C}$, (c) as-prepared IO-IA, and (d) as-prepared CD-IA nanoparticles.

The uncoated oxides (IO-IP) heated to $300^{\circ} \mathrm{C}$ were found to reach the highest magnetic saturation of approximately $60 \mathrm{emu} / \mathrm{g}$ as expected. With the addition of PVA, there is a significant drop in $M_{s}$, which is attributed to the polymer. 


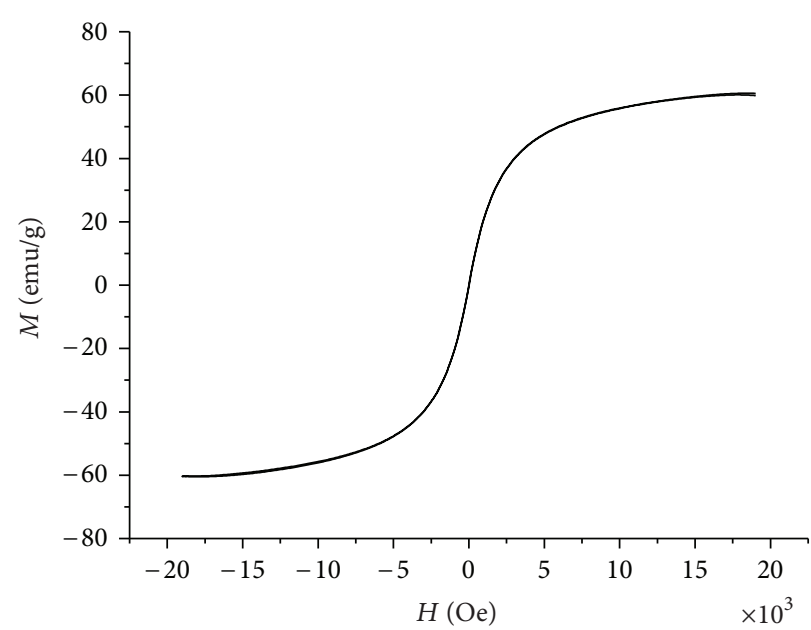

(a)

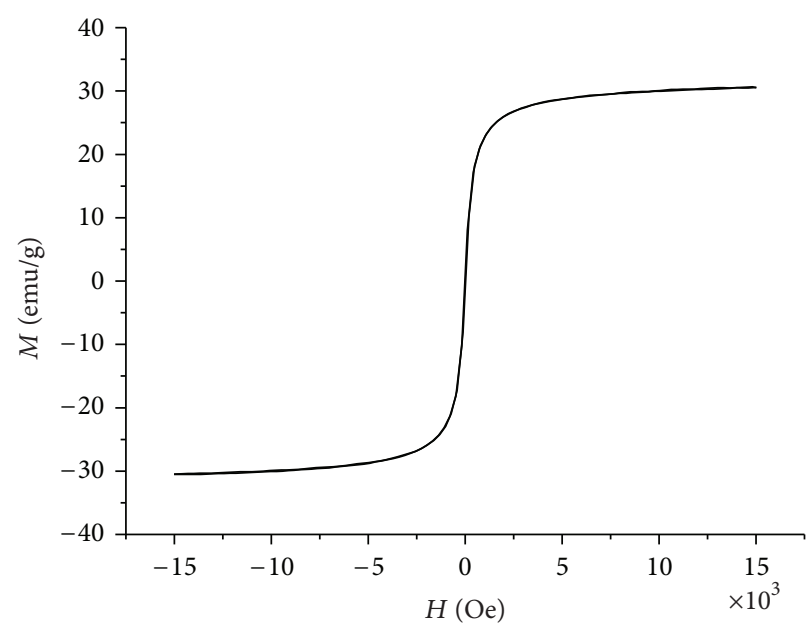

(c)

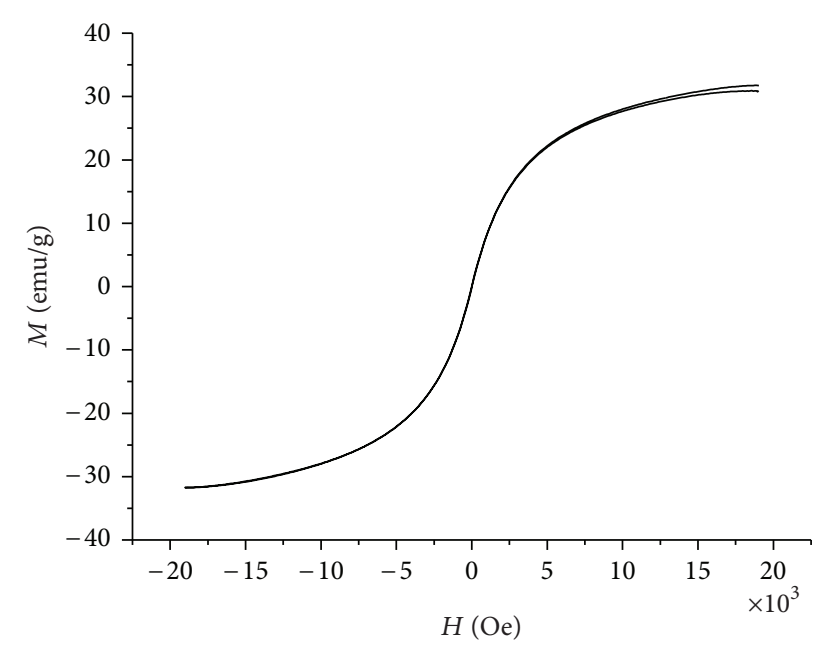

(b)

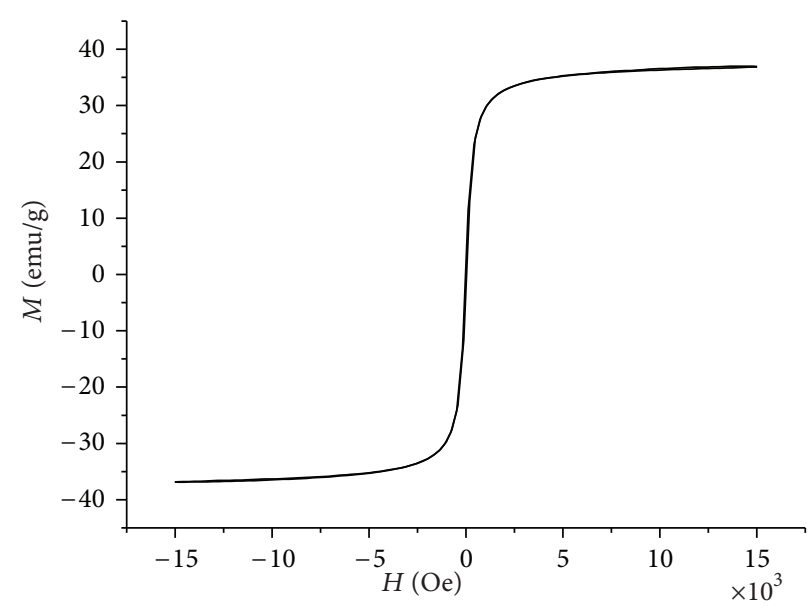

(d)

FIGURE 3: Magnetic measurements of (a) IO-IP heated at $300^{\circ} \mathrm{C}$, (b) PVA-IO heated at $300^{\circ} \mathrm{C}$, (c) as-prepared IO-IA, and (d) as-prepared CD-IA nanoparticles.

It was anticipated that a polymer coating would decrease the magnetization; here; it is decreased by half. The iron oxides synthesized from iron acetate were found to have magnetic saturations much less than those uncoated and produced by iron pentacarbonyl precursors. The CD-IA oxides unexpectedly reached a higher degree of magnetization of approximately $36.92 \mathrm{emu} / \mathrm{g}$, compared to that of the uncoated oxides (IO-IA) which reached approximately $31.32 \mathrm{emu} / \mathrm{g}$. The increase in magnetization of CD-IA is most likely due to the presence of the high crystalline nature of particles, which are ultimately more magnetic.

For comparison, we have noted that the saturation magnetization and coercive field for commercial [34] $\mathrm{Fe}_{3} \mathrm{O}_{4}$ are $96.3 \mathrm{emu} / \mathrm{g}$ and $293 \mathrm{Oe}$, respectively. However, in our case, the magnetite particles are much smaller than the commercial magnetite; the magnetization of these magnetite nanoparticles at $1.6 \mathrm{~T}$ does not fully reach saturation. This huge difference in magnetization and coercive field is a clear indication of the nanostructure of the samples. The total magnetization of a specimen consists of small particles and decreases with decreasing particle size due to the increased dispersion in the exchange integral $[35,36]$ and finally reaches superparamagnetic (SPM) state when each particle acts as a single domain dipole moment with suppressed exchange interaction between particles.

Mössbauer spectroscopy was used to determine the fine structure of iron oxide nanoparticles and their relative sizes. The ambient temperature Mössbauer spectra of (a) as-prepared IO-IP, (b) PVA-IO heated at $300^{\circ} \mathrm{C}$, (c) as-prepared IOIA, and (d) as-prepared CD-IA are shown in Figure 4 wherein one can see a progression from rapidly relaxing (super) paramagnetism (a) to slow paramagnetic relaxation (d) but not a fully resolved magnetic hyperfine splitting. Stoichiometric magnetite can be written as $\left[\mathrm{Fe}^{3+}\right]_{\text {tet }}\left[\mathrm{Fe}^{2+} \mathrm{Fe}^{3+}\right]_{\text {oct }} \mathrm{O}_{4}[16]$ and displays two sets of superimposed hyperfine resonance lines representing the iron at the octahedral and tetrahedral sites where only one set of lines is present in $\mathrm{Fe}_{2} \mathrm{O}_{3}$. Also, magnetite displays hyperfine splitting at room temperature, that 


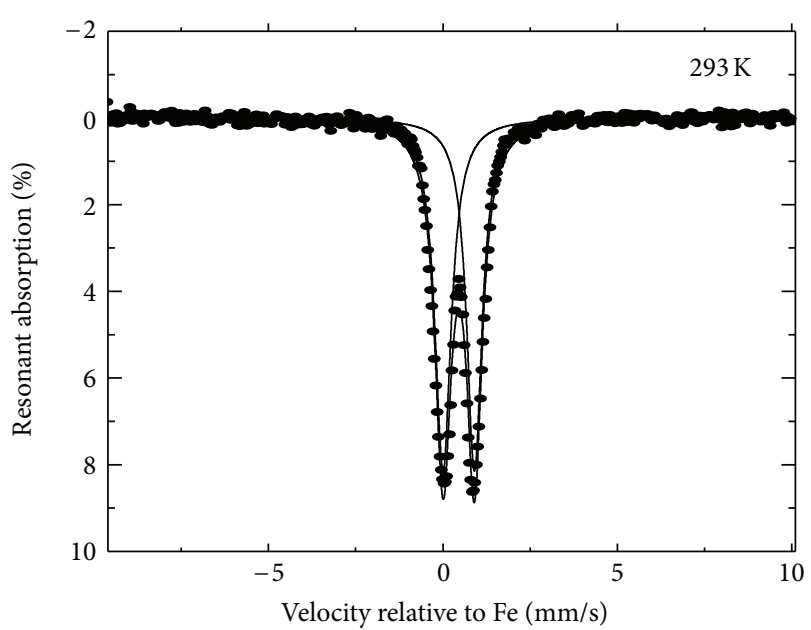

(a)

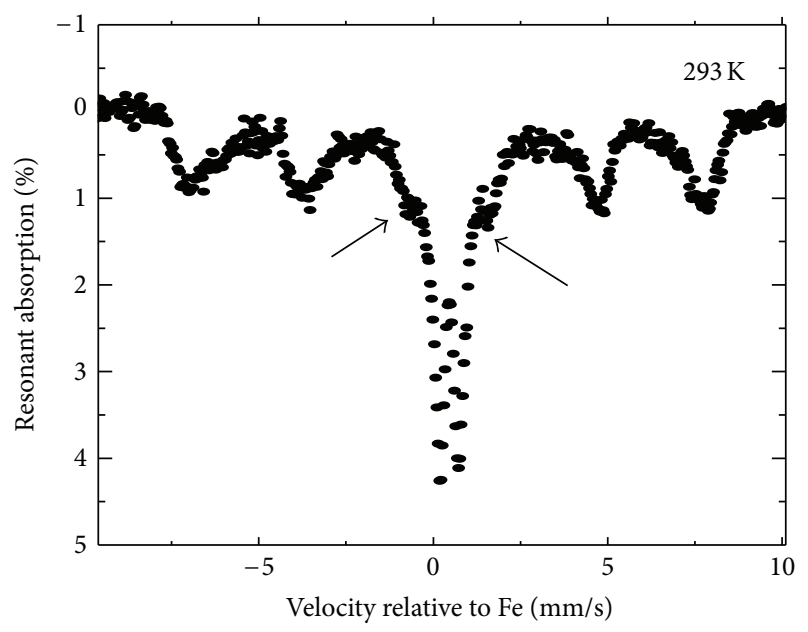

(c)

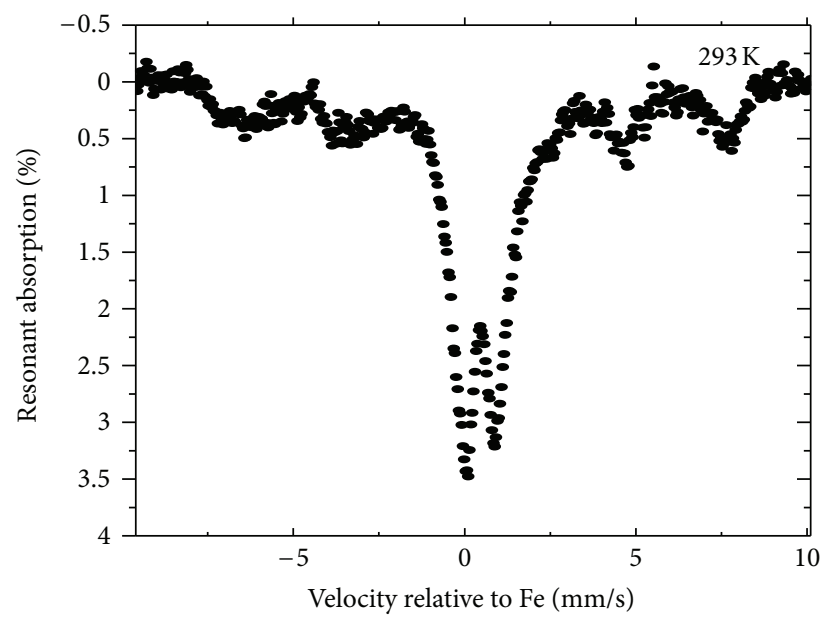

(b)

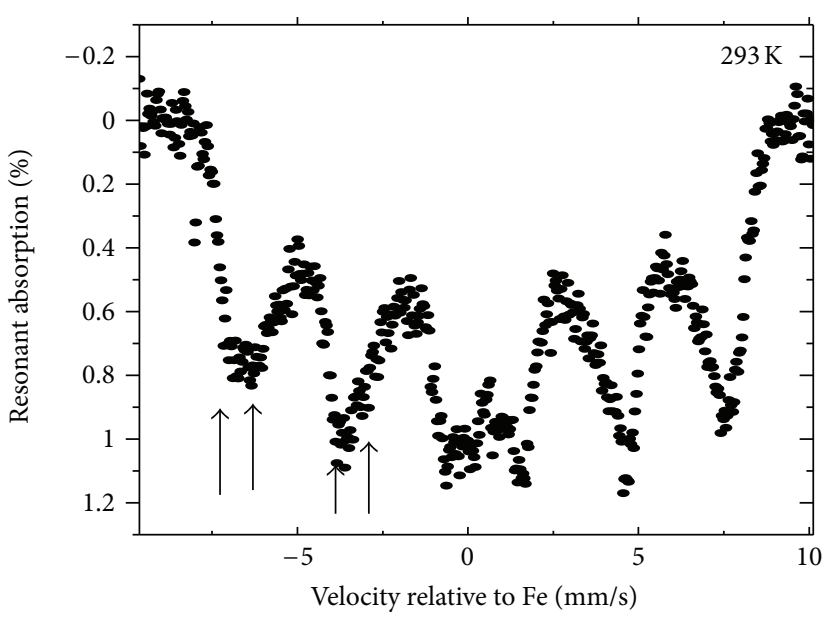

(d)

FIGURE 4: Mössbauer spectra of (a) as-prepared IO-IP, (b) PVA-IO heated at 300 C, (c) as-prepared IO-IA, and (d) as-prepared CD-IA.

is absent in maghemite. Spectra of IO-IP (Figure 4(a)) show evidence of the characteristic magnetite splitting.

Figure 4(b) which is of the PVA-coated particles illustrate widening peaks and a developing sextet, indicating an increase in particle size which is expected due to the additional polymer coating. The sextet becomes increasingly evident in the oxides synthesized from iron acetate, signifying a greater increase in particle size. As expected, the CD-IA has the most defined sextet, indicative of the largest size particles. This is a typical, systematic trend with increasing particle (actually magnetic domain) sizes for a fixed temperature and is also observed by other researchers $[37,38]$ for a specific case of hematite $\left(\mathrm{Fe}_{2} \mathrm{O}_{3}\right)$ for a number of specific particle sizes. That is, with increasing particle size, the blocking temperature for the transition from rapidly relaxing superparamagnetism (for which the long time average molecular field is zero) to long range ordered bulk magnetic behavior increases. Thus the hierarchy for the particle size of the present samples implied by the ambient temperature results is particle size $(\mathrm{a})<(\mathrm{b})<$ (c) $<$ (d). On the other hand, for a fixed (small) particle size, one sees effects similar to those of increasing particle size (at fixed temperature) by decreasing the temperature [39]. The spectrum of the largest particle size is for (d), of Figure 4 begins to exhibit the low velocity doublets (indicated by vertical arrows in the figure) as seen in the larger particle size bulk $\mathrm{Fe}_{3} \mathrm{O}_{4}$. This confirms that the syntheses procedures used for the preparation of samples (a) through (d) maintain the intrinsic " $\mathrm{Fe}_{3} \mathrm{O}_{4}$ " identity of these materials.

Toxicity studies were carried out to determine the effect of the as-prepared coated and uncoated iron oxide nanoparticles on human cell viability at increasing concentrations and exposure time. The cytotoxicity of the nanoparticles was evaluated in HEp-2 cell line by the MTS assay. The nanoparticle concentrations ranged from 5 to $400 \mu \mathrm{g} / \mathrm{mL}$ which is well above the conventional drug dosage concentration of $2 \mu \mathrm{g} / \mathrm{mL}$. The cell viability was observed at 24,48 , and 72 hours. $5 \mu \mathrm{g} / \mathrm{mL}$ of IO-IP and PVA-IO were added to the cells, $90 \%$ of the cell viability were observed. Cell viability decreased to $80 \%$ when IO-IP and PVA-IO concentrations 


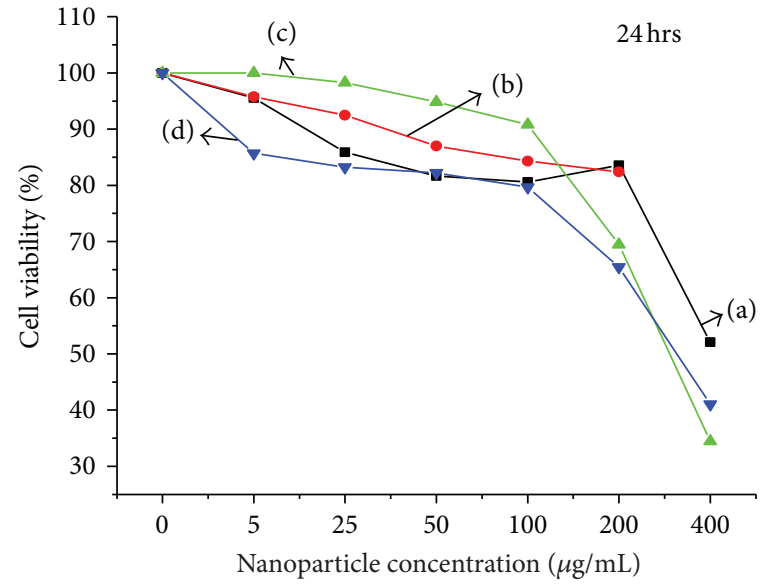

$\begin{array}{ll}\rightarrow \text { (a) IO-IP } & \longrightarrow \text { (c) CD-IO } \\ \longrightarrow \text { (b) PVA-IO } & \rightarrow \text { (d) IO-IA }\end{array}$

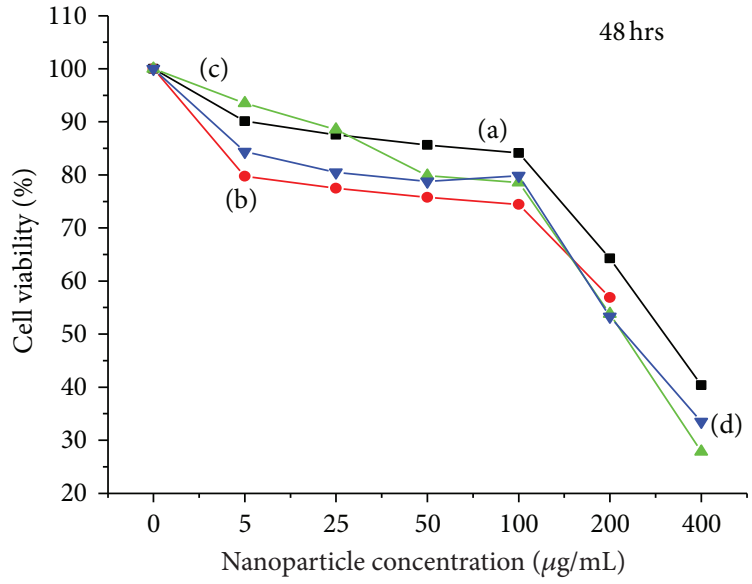

(a) IO-IP

(b) PVA-IO $\rightarrow-(\mathrm{c}) \mathrm{CD}-\mathrm{IO}$

$\rightarrow$ (d) IO-IA

(a)

(b)

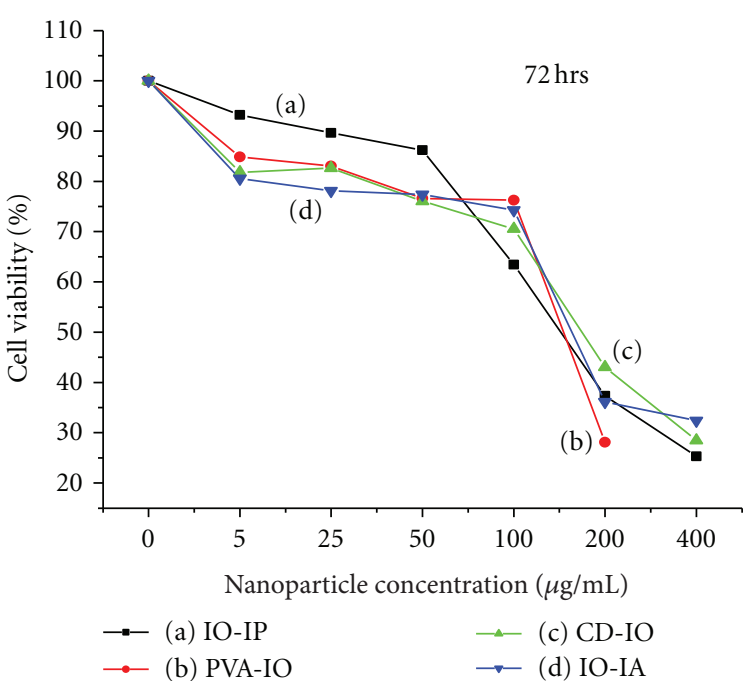

(c)

FIGURE 5: Toxicity studies of as-prepared oxide nanoparticles evaluated in HEp-2 cell lines by MTS assay at (a) 24 h, (b) 48 h, and (c) 72 h.

were increased to $200 \mu \mathrm{g} / \mathrm{mL}$ after $24 \mathrm{~h}$ after infection. There was also a $80 \%$ of the cell viability when $100 \mu \mathrm{g} / \mathrm{mL}$ of CDIA and IO-IA were added to the cells. Cell viability continued decreasing about $60 \%$ when CD-IA and IO-IA were increased to $200 \mu \mathrm{g} / \mathrm{mL}$ after $24 \mathrm{~h}$ after infection (Figure 5(a)). At the exposure time $(48 \mathrm{~h})$ and concentration $(100 \mu \mathrm{g} / \mathrm{mL})$, the cells sustained at least $85 \%$ cell viability (Figure 5(b)). But, cell death was more prominent when cells were analyzed after $72 \mathrm{~h}$ as shown in Figure 5(c). Overall, all the particles were determined to have minimal toxicity. As the exposure time increased, the coatings on the nanoparticles became less effective.

\section{Conclusions}

Uncoated and coated $\mathrm{Fe}_{3} \mathrm{O}_{4}$ nanoparticles were prepared using simple one-step synthesis followed by heat treatments as needed. The use of ultrasonic chemistry provides an easy method to produce both coated and uncoated iron oxide nanoparticles that are of similar size, shape, and crystallinity by either the addition or omission of a polymer. In some instances, the polymer presence does decrease the potential magnetic susceptibility; however it provides an environment for drug loading. From toxicity studies, both the coated and uncoated particles were determined to have low toxicity.

\section{Acknowledgments}

The authors would like to thank the NSF-IGERT, NSFRISE, and NSF-EPSCoR for their financial support. They also would like to thank Dr. J. W. Harrell's from the University of Alabama, MINT Center, for allowing them to use their research facilities. 


\section{References}

[1] D. L. J. Thorek, A. K. Chen, J. Czupryna, and A. Tsourkas, "Superparamagnetic iron oxide nanoparticle probes for molecular imaging," Annals of Biomedical Engineering, vol. 34, no. 1, pp. 23-38, 2006.

[2] E. Amstad, T. Gillich, I. Bilecka, M. Textor, and E. Reimhult, "Ultrastable iron oxide nanoparticle colloidal suspensions using dispersants with catechol-derived anchor groups," Nano Letters, vol. 9, no. 12, pp. 4042-4048, 2009.

[3] R. Qiao, C. Yang, and M. Gao, "Superparamagnetic iron oxide nanoparticles: from preparations to in vivo MRI applications," Journal of Materials Chemistry, vol. 19, no. 35, pp. 6274-6293, 2009.

[4] S. T. Amyn and K. Pei-Yoong, "Synthesis, properties, and applications of magnetic iron oxide nanoparticles," Progress in Crystal Growth and Characterization of Materials, vol. 55, no. 1-2, pp. 22-45, 2009.

[5] L. Wang, J. Luo, M. M. Maye et al., "Iron oxide-gold coreshell nanoparticles and thin film assembly," Journal of Materials Chemistry, vol. 15, no. 18, pp. 1821-1832, 2005.

[6] K. Tanaka, N. Kitamura, M. Morita, T. Inubushi, and Y. Chujo, "Assembly system of direct modified superparamagnetic iron oxide nanoparticles for target-specific MRI contrast agents," Bioorganic and Medicinal Chemistry Letters, vol. 18, no. 20, pp. 5463-5465, 2008.

[7] M. Gonzales-Weimuller, M. Zeisberger, and K. M. Krishnan, "Size-dependant heating rates of iron oxide nanoparticles for magnetic fluid hyperthermia," Journal of Magnetism and Magnetic Materials, vol. 321, no. 13, pp. 1947-1950, 2009.

[8] B. Gaihre, M. S. Khil, D. R. Lee, and H. Y. Kim, "Gelatincoated magnetic iron oxide nanoparticles as carrier system: drug loading and in vitro drug release study," International Journal of Pharmaceutics, vol. 365, no. 1-2, pp. 180-189, 2009.

[9] D. L. Leslie-Pelecky, V. D. Labhasetwar, and R. H. Kraus, Advanced Magnetic Nanostructures, Kluwer, New York, NY, USA, 2007.

[10] D. K. Kim, Y. Zhang, W. Voit, K. V. Rao, and M. Muhammed, "Synthesis and characterization of surfactant-coated superparamagnetic monodispersed iron oxide nanoparticles," Journal of Magnetism and Magnetic Materials, vol. 225, no. 1-2, pp. 30-36, 2001.

[11] T. Neuberger, B. Schöpf, H. Hofmann, M. Hofmann, and B. Von Rechenberg, "Superparamagnetic nanoparticles for biomedical applications: possibilities and limitations of a new drug delivery system," Journal of Magnetism and Magnetic Materials, vol. 293, no. 1, pp. 483-496, 2005.

[12] R. Asmatulu, M. A. Zalich, R. O. Claus, and J. S. Riffle, "Synthesis, characterization and targeting of biodegradable magnetic nanocomposite particles by external magnetic fields," Journal of Magnetism and Magnetic Materials, vol. 292, pp. 108-119, 2005.

[13] V. P. Torchilin, "Drug targeting," European Journal of Pharmaceutical Sciences, vol. 11, no. 2, pp. S81-S91, 2000.

[14] F. C. Maluf and D. Spriggs, "Anthracyclines in the treatment of gynecologic malignancies," Gynecologic Oncology, vol. 85, no. 1, pp. 18-31, 2002.

[15] M. A. Morales, T. K. Jain, V. Labhasetwar, and D. L. LesliePelecky, "Magnetic studies of iron oxide nanoparticles coated with oleic acid and Pluronic block copolymer," Journal of Applied Physics, vol. 97, no. 10, Article ID 10Q905, 3 pages, 2005.
[16] I. Banerjee, Y. B. Khollam, C. Balasubramanian et al., "Preparation of $\gamma-\mathrm{Fe}_{2} \mathrm{O}_{3}$ nanoparticles using DC thermal arc-plasma route, their characterization and magnetic properties," Scripta Materialia, vol. 54, no. 7, pp. 1235-1240, 2006.

[17] Z. Surowiec, M. Wiertel, M. Budzyński, J. Sarzyński, and J. Goworek, "Magnetite nanowires in MCM-41 type mesoporous silica templates," Journal of Non-Crystalline Solids, vol. 354, no. 35-39, pp. 4271-4274, 2008.

[18] P. Tartaj, M. Del Puerto Morales, S. Veintemillas-Verdaguer, T. González-Carreño, and C. J. Serna, "The preparation of magnetic nanoparticles for applications in biomedicine," Journal of Physics D, vol. 36, no. 13, pp. R182-R197, 2003.

[19] J. Huang, H. Pen, Z. Xu, and C. Yi, "Magnetic $\mathrm{Fe}_{3} \mathrm{O}_{4} /$ poly (styrene-co-acrylamide) composite nanoparticles prepared by microwave-assisted emulsion polymerization," Reactive and Functional Polymers, vol. 68, no. 1, pp. 332-339, 2008.

[20] J. Pinkas, V. Reichlova, R. Zboril, Z. Moravec, P. Bezdicka, and J. Matejkova, "Sonochemical synthesis of amorphous nanoscopic iron(III) oxide from $\mathrm{Fe}(\mathrm{acac})_{3}$," Ultrasonics Sonochemistry, vol. 15, no. 3, pp. 257-264, 2008.

[21] K. S. Suslick, S. B. Choe, A. A. Cichowlas, and M. W. Grinstaff, "Sonochemical synthesis of amorphous iron," Nature, vol. 353, no. 6343, pp. 414-416, 1991.

[22] R. Vijayakumar, Y. Koltypin, I. Felner, and A. Gedanken, "Sonochemical synthesis and characterization of pure nanometersized $\mathrm{Fe}_{3} \mathrm{O}_{4}$ particles," Materials Science and Engineering A, vol. 286, no. 1, pp. 101-105, 2000.

[23] A. Gedanken, "Using sonochemistry for the fabrication of nanomaterials," Ultrasonics Sonochemistry, vol. 11, no. 2, pp. 47-55, 2004.

[24] G. Q. Zhang, H. P. Wu, M. Y. Ge, Q. K. Jiang, L. Y. Chen, and J. M. Yao, "Ultrasonic-assisted preparation of monodisperse iron oxide nanoparticles," Materials Letters, vol. 61, no. 11-12, pp. 2204-2207, 2007.

[25] A. Gedanken, Ultrasonic Processing to Produce Nanoparticles, Encyclopedia of Materials, Science and Technology Elsevier Science, Oxford, UK, 2008.

[26] P. Dallas, A. B. Bourlinos, D. Niarchos, and D. Petridis, "Synthesis of tunable sized capped magnetic iron oxide nanoparticles highly soluble in organic solvents," Journal of Materials Science, vol. 42, no. 13, pp. 4996-5002, 2007.

[27] R. V. Ramanujan and Y. Y. Yeow, "Synthesis and characterisation of polymer-coated metallic magnetic materials," Materials Science and Engineering C, vol. 25, no. 1, pp. 39-41, 2005.

[28] J. L. Arias, V. Gallardo, S. A. Gómez-Lopera, R. C. Plaza, and A. V. Delgado, "Synthesis and characterization of poly(ethyl-2cyanoacrylate) nanoparticles with a magnetic core," Journal of Controlled Release, vol. 77, no. 3, pp. 309-321, 2001.

[29] L. Seung-Jun, J. Jong-Ryul, S. Sung-Chul et al., "Magnetic enhancement of iron oxide nanoparticles encapsulated with poly(D,L-latide-co-glycolide)," Colloids and Surfaces A, vol. 255, no. 1-3, pp. 19-25, 2005.

[30] H. Yaci Acar, R. S. Garaas, F. Syud, P. Bonitatebus, and A. M. Kulkarni, "Superparamagnetic nanoparticles stabilized by polymerized PEGylated coatings," Journal of Magnetism and Magnetic Materials, vol. 293, no. 1, pp. 1-7, 2005.

[31] P. J. Reséndiz-Hernández, O. S. Rodríguez-Fernández, and L. A. García-Cerda, "Synthesis of poly(vinyl alcohol)-magnetite ferrogel obtained by freezing-thawing technique," Journal of Magnetism and Magnetic Materials, vol. 320, pp. e373-e376, 2008. 
[32] T. K. Jain, M. A. Morales, S. K. Sahoo, D. L. Leslie-Pelecky, and V. Labhasetwar, "Iron oxide nanoparticles for sustained delivery of anticancer agents," Molecular Pharmaceutics, vol. 2, no. 3, pp. 194-205, 2005.

[33] S. Hanessian, J. A. Grzyb, F. Cengelli, and L. Juillerat-Jeanneret, "Synthesis of chemically functionalized superparamagnetic nanoparticles as delivery vectors for chemotherapeutic drugs," Bioorganic and Medicinal Chemistry, vol. 16, no. 6, pp. 2921-2931, 2008.

[34] X. Cao, "Preparation and characterization of amorphous nanometre sized $\mathrm{Fe}_{3} \mathrm{O}_{4}$ powder," Journal of Materials Chemistry, vol. 7, no. 6, pp. 1007-1009, 1997.

[35] S. R. Elliott, Physics of Amorphous Materials, Longman, London, UK, 1984.

[36] C. C. Daniela, M. Gabriela, P. Luminița, and D. Lucian, "Synthesis and characterization of maltol modified magnetite nanoparticles," Revue Roumaine de Chimie, vol. 55, no. 2, pp. 131-135, 2010.

[37] N. N. Greenwood and T. C. Gibb, Mössbauer Spectroscopy, Chapman and Hall, London, UK, 1971.

[38] K. R. Vijaya, Y. Koltypin, X. N. Xu, Y. Yeshurun, A. Gedanken, and I. Felner, "Fabrication of magnetite nanorods by ultrasound irradiation," Journal of Applied Physics, vol. 89, no. 11, p. 6324, 2001.

[39] W. Kündig, H. Bömmel, G. Constabaris, and R. H. Lindquist, "Some properties of supported small $\alpha-\mathrm{Fe}_{2} \mathrm{O}_{3}$ particles determined with the Mössbauer effect," Physical Review, vol. 42, no. 2, pp. 327-333, 1966. 

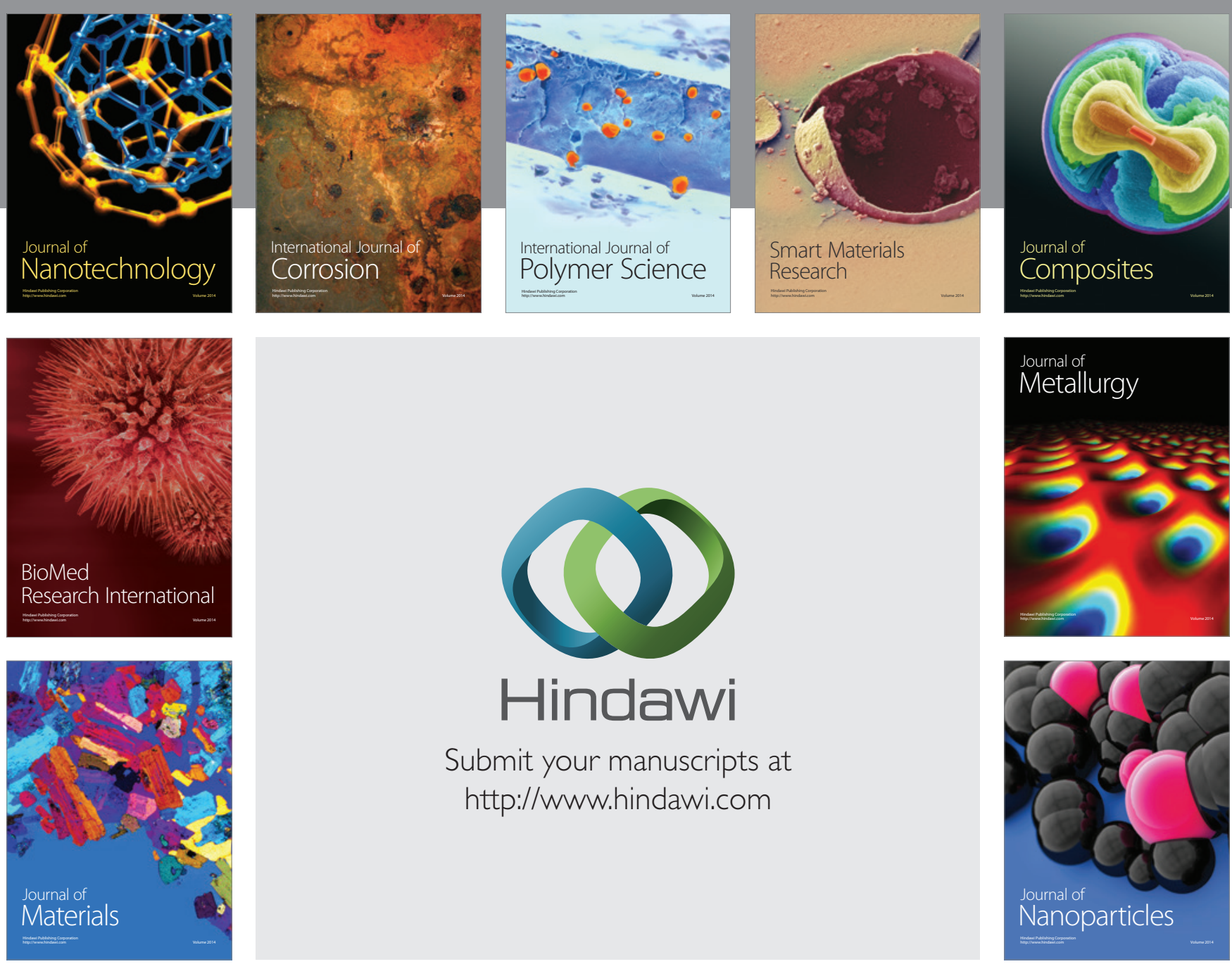

Submit your manuscripts at http://www.hindawi.com
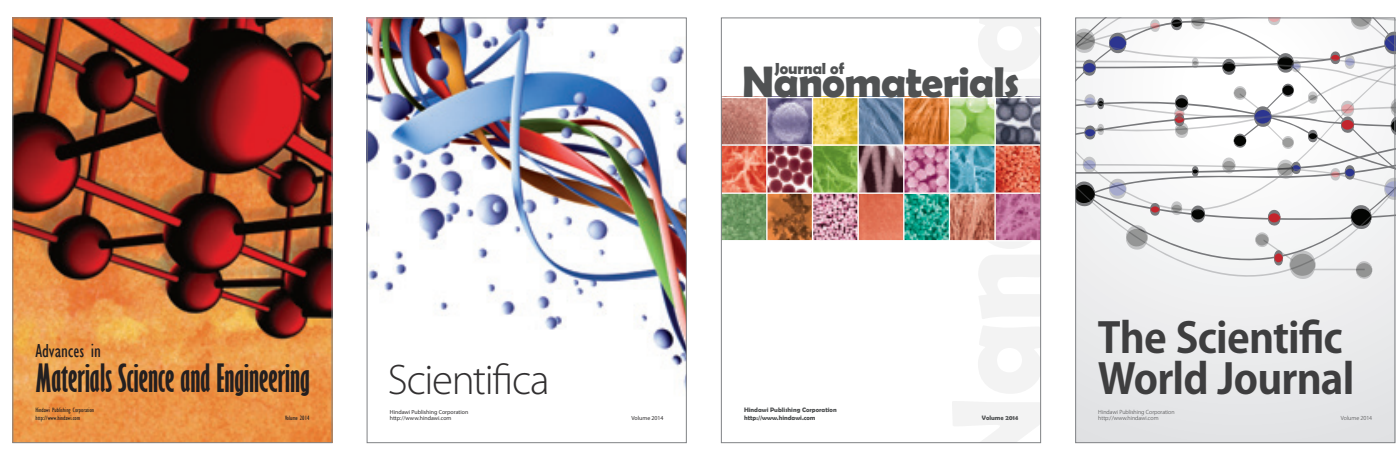

\section{The Scientific World Journal}
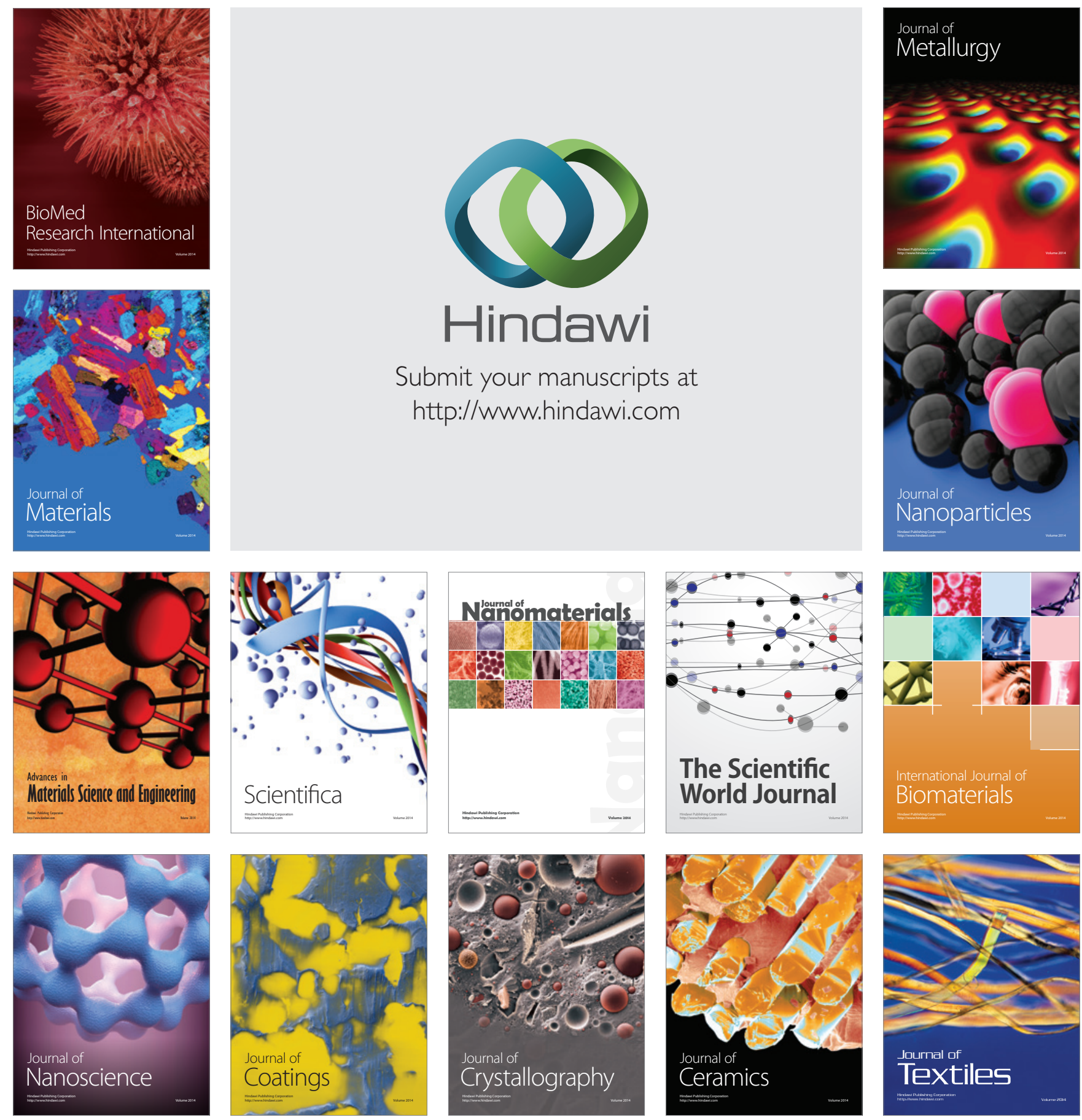